\title{
Effects of Pyridine and Furan Pretreatment on the Corrosion Resistance of Rust Coating on Mild Steel
}

\author{
Yinze Zuo, Liang Chen, Yu Wang, Yunxia Guo, Xingling Shi , Yanmin Gao \\ School of Materials Science and Engineering, Jiangsu University of Science and Technology, \\ Zhenjiang 212003 \\ *E-mail: sxl_just@163.com,ymgjust@126.com
}

doi: $10.20964 / 2017.10 .03$

Received: 16 May 2017 / Accepted: 12 July 2017 / Published: 12 September 2017

\begin{abstract}
Pre-processing of a metal surface before coating is a key factor that affects the coating performance. This phenomenon has been puzzling people for a long time. In this paper, a new type of preprocessing using heterocyclic compounds, pyridine and furan, were applied to address this problem. The tests show that the rust layers of mild steel treated by pyridine and furan are more compact than the untreated layers. The corrosion rate of the mild steel with a rust layer treated by pyridine is lower than that of the samples with furan treatment and without treatment, while the impedance is also the largest. The adhesion of an epoxy-polyvinylbutyral (EP-PVB) coating, which is painted on rust layers with pyridine and furan pretreatment, is much stronger. Moreover, the corrosion resistance of EP-PVB coatings that are painted onto the rust layers with pretreatment is much better than that of the coatings that are directly painted onto the rust layer without pretreatment. The impedance of EP-PVB coatings that are painted onto the rust layers with pretreatment is much higher than that of the EP-PVB coating that is directly painted onto the rust layer without pretreatment.
\end{abstract}

Keywords: corrosion, surface treatment, rust coating, heterocyclic compounds, electrochemical test

\section{FULL TEXT}

(C) 2017 The Authors. Published by ESG (www.electrochemsci.org). This article is an open access article distributed under the terms and conditions of the Creative Commons Attribution license (http://creativecommons.org/licenses/by/4.0/). 